\title{
NASA Near Earth Network (NEN) and Space Network (SN) CubeSat Communications
}

\author{
Scott H. Schaire ${ }^{1}$, Harry Shaw ${ }^{2}$, Serhat Altunc ${ }^{3}$,George Bussey ${ }^{4}$, Peter Celeste ${ }^{5}$, Obadiah Kegege ${ }^{6}$, Yen Wong ${ }^{7}$, \\ Yuwen Zhang ${ }^{8}$, Chitra Patel ${ }^{9}$, David Raphael ${ }^{10}$, Jacob Burke ${ }^{11}$, La Vida Cooper ${ }^{12}$ \\ Goddard Space Flight Center, Greenbelt, MD 20771 \\ James Schier ${ }^{13}$, William Horne ${ }^{14}$, David Pierce ${ }^{15}$ \\ NASA Headquarters, Washington, DC 20546
}

\begin{abstract}
There has been a recent trend to increase capability and drive down the Size, Weight and Power (SWAP) of satellites. NASA scientists and engineers across many of NASA's Mission Directorates and Centers are developing exciting CubeSat concepts and welcome potential partnerships for CubeSat endeavors. From a "Telemetry, Tracking and Command (TT\&C) Systems and Flight Operations for Small Satellites" point of view, small satellites including CubeSats are a challenge to coordinate because of existing small spacecraft constraints, such as limited SWAP and attitude control, and the potential for high numbers of operational spacecraft. The NASA Space Communications and Navigation (SCaN) Program's Near Earth Network (NEN) and Space Network (SN) are customer driven organizations that provide comprehensive communications services for space assets including data transport between a mission's orbiting satellite and its Mission Operations Center (MOC). This paper presents how well the SCaN networks, SN and NEN, are currently positioned to support the emerging small small satellite and CubeSat market as well as planned enhancements for future support.
\end{abstract}

\section{Introduction}

This paper discusses the capabilities of the NEN and SN in the context of CubeSats including how the NEN and SN are planning to support upcoming CubeSat missions. The SN has developed concepts on how multiple access capability could help locate CubeSats and provide low-latency early warning systems. The evolution of high-data rate NEN-compatible radios enable CubeSats to take advantage of the NEN global network of 11-meter class groundstations, and are consistent with appropriate frequency bands and licensing. Radio and antenna development at Goddard Space Flight Center (GSFC) and across industry are facilitating orders of magnitude increases in data rates for CubeSats. Five years ago, CubeSat radios were typically at kilobits per second rates. Today, radios have evolved into the tens of megabits per second. Standardization of radio frequency interfaces and flight and ground communications hardware systems may reduce the amount of time and cost required to obtain frequency authorization

${ }^{1}$ Near Earth Network Wallops Manager, Code 453, NASA Goddard Space Flight Center, Wallops Flight Facility.

2 Senior RF Engineer, Code 566, NASA Goddard Space Flight Center, 8800 Greenbelt Road.

3 Senior RF Engineer, Code 566, NASA Goddard Space Flight Center, 8800 Greenbelt Road.

${ }^{4}$ Senior RF Engineer, Code 566, NASA Goddard Space Flight Center, 8800 Greenbelt Road.

5 Senior RF Engineer, Code 453, NASA Goddard Space Flight Center, 8800 Greenbelt Road.

${ }^{6}$ Senior RF Engineer, Code 566, NASA Goddard Space Flight Center, 8800 Greenbelt Road.

7 Senior RF Engineer, Code 566, NASA Goddard Space Flight Center, 8800 Greenbelt Road.

8 Senior RF Engineer, Code 450, NASA Goddard Space Flight Center, 8800 Greenbelt Road.

9 Senior RF Engineer, Code 450, NASA Goddard Space Flight Center, 8800 Greenbelt Road.

${ }^{10}$ Associate Branch Head, Code 566, NASA Goddard Space Center, 8800 Greenbelt Road.

${ }^{11}$ RF Engineer, Code 566, NASA Goddard Space Flight Center, 8800 Greenbelt Road.

${ }^{12}$ Branch Head, Code 566, NASA Goddard Space Flight Center, 8800 Greenbelt Road.

${ }^{13}$ Space Communications and Navigation (SCaN) Chief Architect, NASA Headquarters, 300 E Street S.W.

${ }^{14}$ Senior Spectrum Technology Advisor, NASA Headquarters, 300 E Street S.W.

${ }^{15}$ Senior Program Executive for Suborbital Programs, NASA Headquarters, 300 E Street S.W.

American Institute of Aeronautics and Astronautics 
and perform compatibility and end-to-end testing. Network architectures need to consider daily data volume, numbers of simultaneous CubeSats over particular ground stations sites, potential for multiple CubeSats within the same beam, in addition to data rate.

\section{CubeSat Science}

NASA's Science Mission Directorate (SMD) is developing strategies to leverage the growing capabilities of small satellites and nano-satellite technologies to address fundamental scientific, technological, and educational investigations. While CubeSats have historically been used as teaching tools and technology demonstrations, recently selected flight projects are now showing that they can accomplish significant Earth and space science goals as well. Many U.S. Government, academic, and industry partners now plan to use CubeSats as platforms to enable science, mature technologies, complement ground-based systems, conduct long term monitoring and enable workforce development. Combined with NASA's CubeSat Launch Initiative (CSLI) and the wide array of ground network systems for these secondary payloads, the opportunities for CubeSats is burgeoning. Finally, low-cost CubeSats provide exciting opportunities for promoting STEM and inspiring students through hands-on student involvement in space-based scientific research, fulfilling a crucial goal for the agency and the nation.

The CubeSat page at NASA shows NASA CubeSat missions for technology and science, see http://www.nasa.gov/mission_pages/cubesats/index.html. Science missions on CubeSats continue to become more sophisticated, yielding significant return, comparable to science returns from much larger, more expensive, traditional non-CubeSat missions. One such future mission is CubeSat to study Solar Particles, or CuSP shown in Figure 1. CuSP is a six-unit (6U) CubeSat, meaning it has a total volume of about six liters, and dimensions of approximately 4" by 8 " by 12 ". The sun releases a constantly-flowing stream of particles and magnetic fields, known as the solar wind. When coronal mass ejections (CME's) interspersed within the solar wind, or even a particularly fast stream of solar wind - reach Earth, they can interact with Earth's magnetic field, creating what's called a geomagnetic storm. To understand the effects of geomagnetic storms on Earth, scientists want to track how the space environment changes and develops between the sun and Earth.

CuSP, like many other single CubeSats is a testing ground for a later constellation of a greater number of CubeSats. "Right now, it's like we're trying to understand weather for the entire Pacific Ocean with just a handful of weather stations," said Eric Christian, lead GSFC scientist for CuSP. "We need to collect data from more locations." The cost of putting together large numbers of tranditional non-CubeSat satellites is prohibitive. Though the satellites can only carry a few instruments apiece, they're relatively inexpensive to launch because of their small mass and standardized design. "If you had, say, 20 CubeSats in different orbits, you could really start to understand the space environment in three dimensions," said Christian.

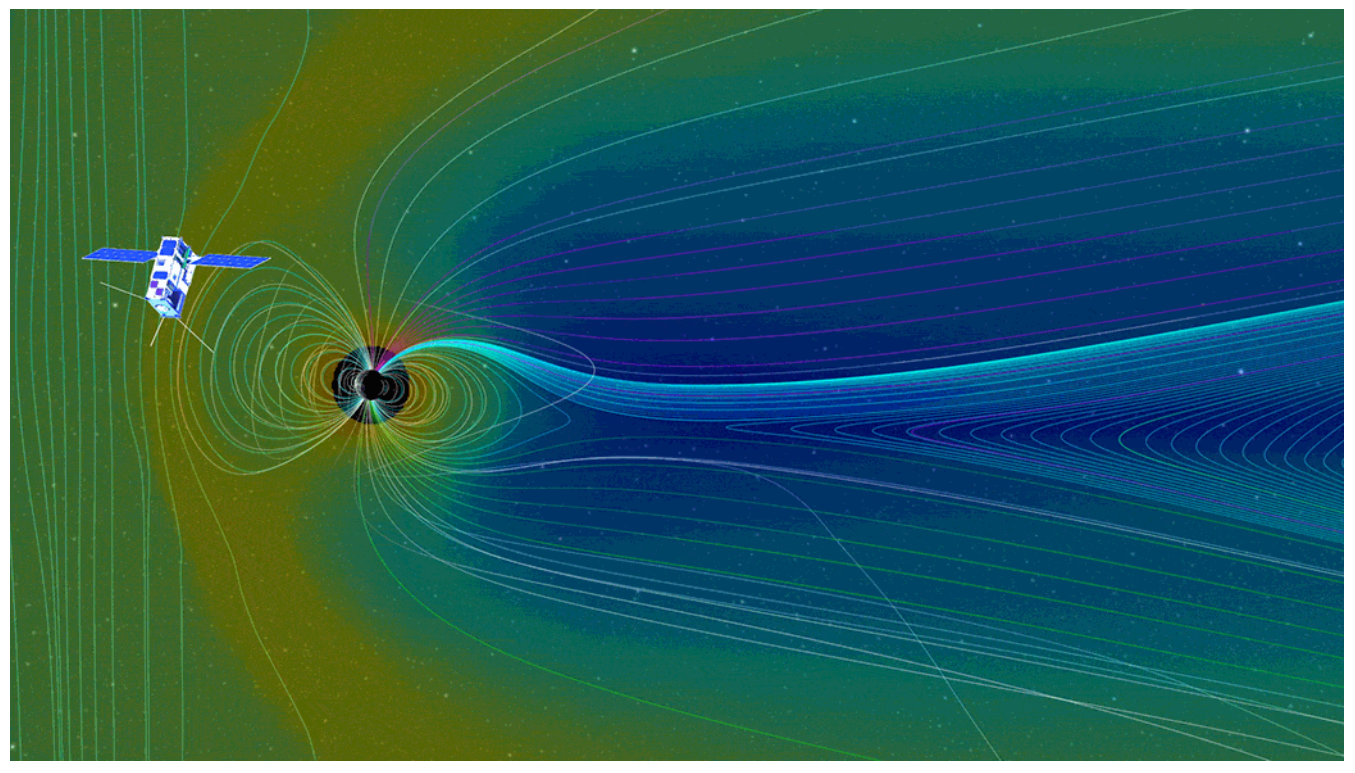


III. Future

CubeSat

Missions

The age of small satellites including

CubeSats is here.

The small satellite communication and navigation needs. The following observations outline several considerations:

- The Market: Per the NASA Spectrum program's list of small satellites, more than 520 small satellites (spacecraft $<100 \mathrm{~kg}$ ) have launched between 2002 and December 2015 (Figure 2) and many more have been identified but not yet launched (1000's including large commercial constellations). Other studies (e.g., SIA ${ }^{1}$, SpaceWorks ${ }^{2}$ ) also document this increase.

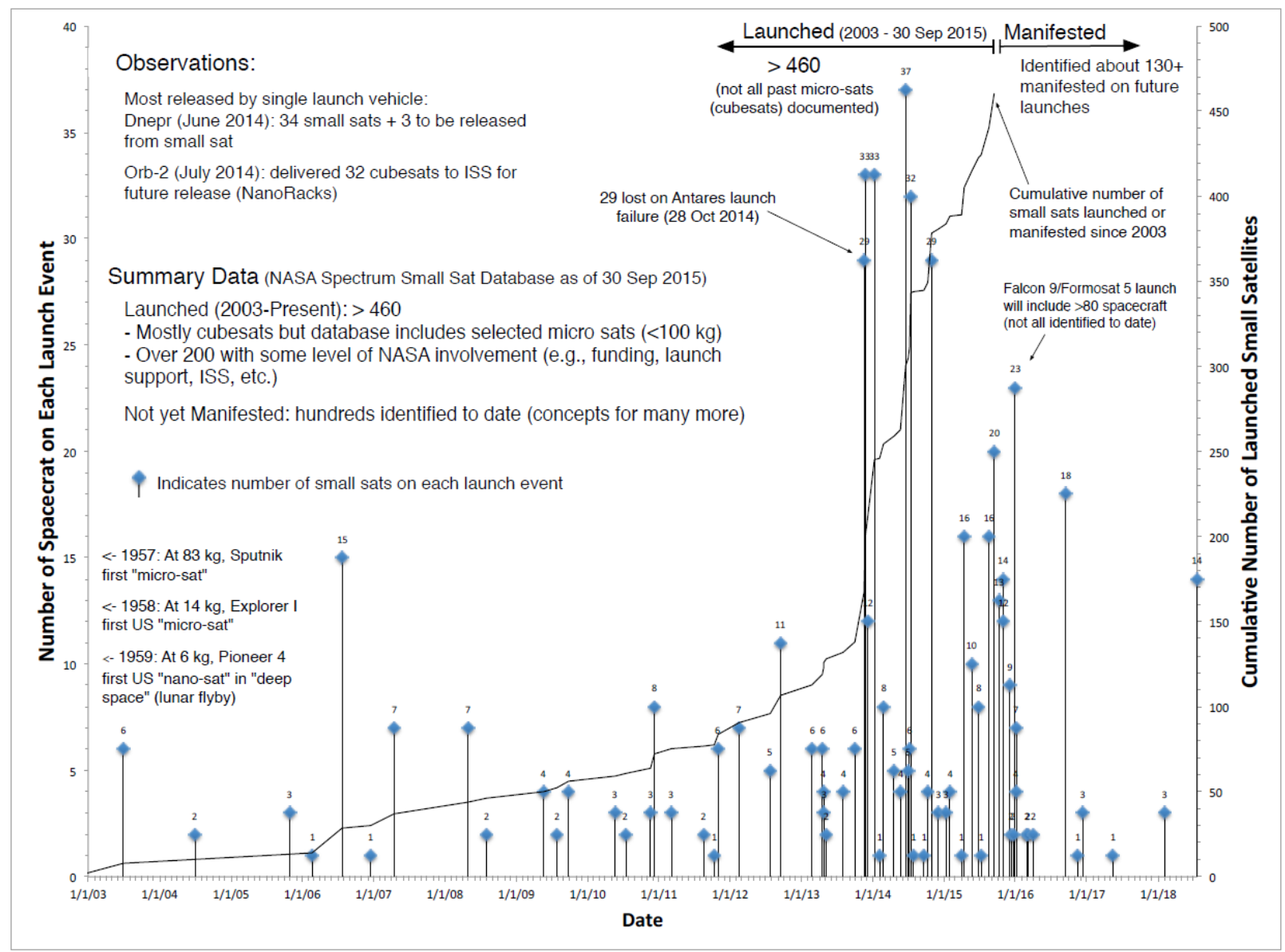

Figure 2. Launches with SmallSats (per NASA/Spectrum data set). Data includes all identified cubesats and most micro-satellites $(<100 \mathrm{~kg})$.

- NASA Activities: NASA, across its mission directorates and Centers, is actively involved in all aspects of small satellite missions including launch support (e.g., the CSLI project, ISS) and technology development (e.g., STMD/SSTP, SMD, STMD's CubeQuest Centennial challenge). Although no one central organization exists in NASA to coordinate or prioritize small satellite activities, NASA's small satellite activities follow the various organizations' traditional areas of work. Applying small satellites to NASA's science and exploration missions is still emerging; for example, SMD is sponsoring a variety of missions, often via grants, with some notable projects such as the Earth Science CYGNSS mission (Oct 2016 launch of eight (8) $18 \mathrm{~kg}$ spacecraft). SMD is also sponsoring both an

American Institute of Aeronautics and Astronautics 
internal study and a National Academies study, co-sponsored by the National Science Foundation (NSF), to identify what science can be obtained using small satellites.

- NASA SCaN. To date, the NASA's SCaN Network elements have not directly supported any CubeSat mission. A few CubeSat missions are now planning to use SCaN services, specifically the Deep Space Network (DSN) and the NEN, but they are, at this time, limited in number. The first NEN supported cubesat mission is STMD's CPOD mission (late 2016).

- Operational Locations: To date, almost all small satellites have operated in low Earth orbit; however, small satellites have and will also operate in highly elliptical orbits, in the cis-lunar area, and in deep space. Thus, communications support will need to address all space locations.

- Spectrum-Communications and Navigation: To date, over 25 frequency bands, from VHF to near infrared/optical laser links, have been or are planned to be used for communicating with small satellites. Many small satellites have used GPS or other satellite-based navigation signals.

- Spectrum-Science Instruments: To date, most science small satellites have used passive sensors, mostly infrared and optical but a few have used radiofrequency radiometers (>100 GHz). Very few (if any) small satellites have used active radiofrequency sensors, but concepts exist for active radars (e.g., $35 \mathrm{GHz}$ ).

- Future. The use of and capabilities for small satellites are clearly increasing. NASA's use of small satellites for its core science and exploration missions will likely increase but to what degree is not yet clear. Recognizing the uncertainty in the numbers and capabilities for future small satellites, concepts and designs of future space communications architectures should consider flexible, responsive approaches that can react to increasing but highly variable and episodic small satellite use.

Given this potential increased use of small spacecraft, NASA NEN and SN are developing strategies to address the communication needs of these missions. Table 1 shows some of the representative missions that requested NASA communication infrastructure support from NEN. This list is highly dynamic subject to funding, schedules, and launch manifests.

Table 1. NASA Networks Representative CubeSat Mission List for NEN.

\begin{tabular}{|l|l|}
\hline Mission & $\begin{array}{l}\text { Launch Date (No } \\
\text { Earlier Than) }\end{array}$ \\
\hline CPOD/PONSFD (A and B) & $10 / 1 / 2016$ \\
\hline SOCON & Mid 2017 \\
\hline iSAT & $11 / 1 / 2017$ \\
\hline CryoCube & $3 / 1 / 2018$ \\
\hline Lunar Ice Cube & $7 / 1 / 2018$ (EM-1) \\
\hline BioSentinel & $7 / 1 / 2018$ (EM-1) \\
\hline Burst Cube & 2019 \\
\hline Propulsion Pathfinder (RASCAL) & TBD \\
\hline
\end{tabular}

Based upon a survey of potentential GSFC CubeSats certain patterns in design emerge. Most of upcoming missions that the NEN or SN would support are LEO missions around 400-500 km with in inclination around 53 degrees. A significant source of CubeSat deployments is via the ISS. A total of thirty-three CubeSats were deployed from the ISS in early 2014. Of those thirty-three, twenty-eight were part of the Flock-1 constellation of Earth-imaging CubeSats. This is why the most common CubeSat proposal design is a $400 \mathrm{~km}, 52$ degree inclination (ISS is at 51.6 degrees). The maximum data volume for any of these users is 10 GBytes $(\mathrm{Gb}) /$ day with the majority of users around 3Gb/day. GSFC has taken the mission set and broken it into 51 Design Reference Missions or DRM's around specific categories:

1. Reference Orbit or Altitude: 400-500;700-900;GeoSychronous; Lunar; L1; Mars

2. Orbital Inclination: 0-28.5;43-61;90-100;

3. Science Volume: (Low) 0-1 Gb; (Medium) 2-5 Gb; (High) 5-20 Gb;

4. Science Type: Earth Science; Space Science;

Based upon analysis of those reference missions to existing network assets, maximum data rate boundaries of 4.4 $\mathrm{Mbp} / \mathrm{s}$ for $\mathrm{S}$ band and $8.8 \mathrm{Mb} / \mathrm{s}$ for $\mathrm{X}$ band designs were obtained with a 2 watt transmitter and a 0 dbi antenna gain. 
The newer proposals are meeting those design criteria, however some of the first CubeSat proposals have lower antenna gains and as a result lower data rates.

The most common CubeSat proposal design currently is a $400 \mathrm{~km}, 52$ degree inclination, Space research service (SRS) or Earth exploration-satellite service (EESS) user, returning $3 \mathrm{~Gb} /$ day in S-Band with a $4.4 \mathrm{Mb} / \mathrm{s}$ data rate with a patch antenna.

\section{A. Capacity of NEN}

In November 2015, the NEN performed a trade study to answer the question of how many CubeSats the network could support. Additionally, the question of what locations could be most beneficial to increase support capability was posed.

The methodology is shown in Figure 3 below. It involves utilizing the software tool Loading Analysis Tool for Telecommunications Engineers (LATTE), a software tool for stochastically generating CubeSat users, and databases of existing ground assets and users. Initially a loading study was computed given the traditional user set and then one with CubeSat users. Those results were analyzed and if all mission requirements were met, additional CubeSat users were added until the NEN and Commercial Sites were unable to meet the network requirements for every user. That data was then parsed and the results were analyzed to determine network capacity, network gaps, and key drivers in the results.

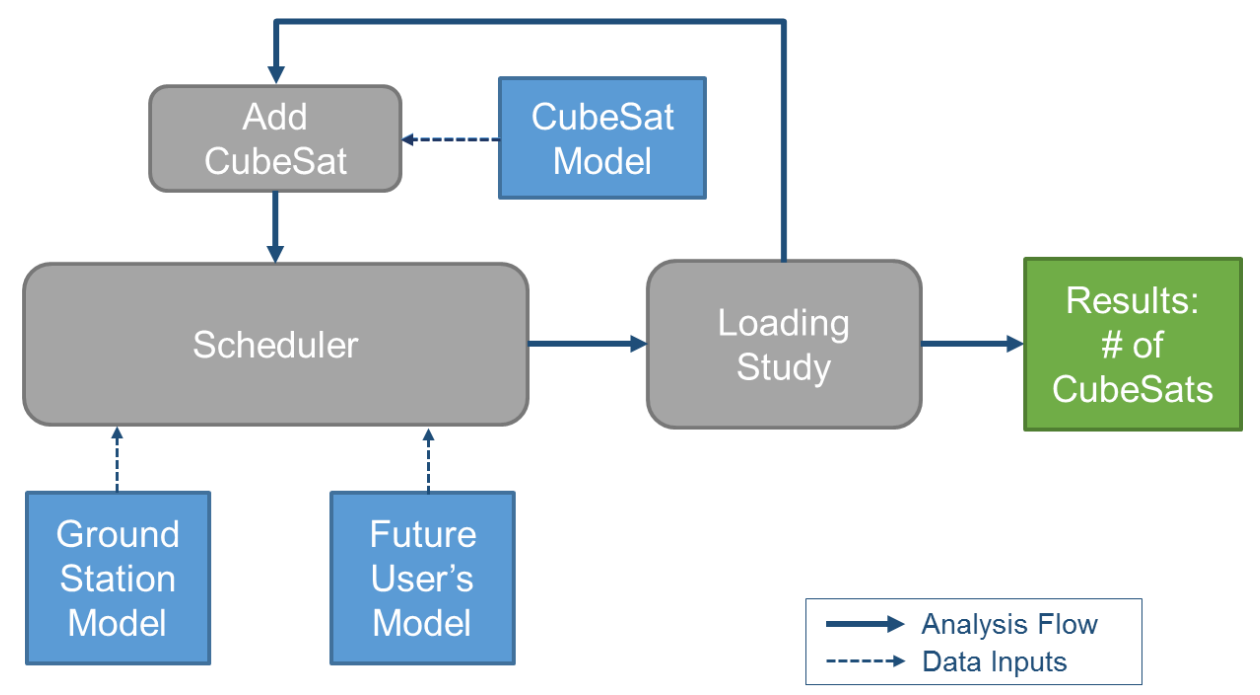

Figure 3 shows a plot of the results of the analysis. The $\mathrm{x}-$ axis represents the number of CubeSats used in the loading analysis, while the stacked

\section{Figure 3. CubeSat Capacity Analysis Model}

bar represents the number of minutes used at specific ground stations to satisfy all the CubeSat users. The red line represents deficit in the number of requested minutes from all satellites and the number of scheduled minutes from all assets. The red line drops negative at 48 satellites meaning that the Near Earth Network and its commercial partners can support 47 satellites provided those satellites adhere to certain assumptions in Table 2 . The results are highly tuned to the assumptions and small changes in the assumptions can produce different answers.

American Institute of Aeronautics and Astronautics 


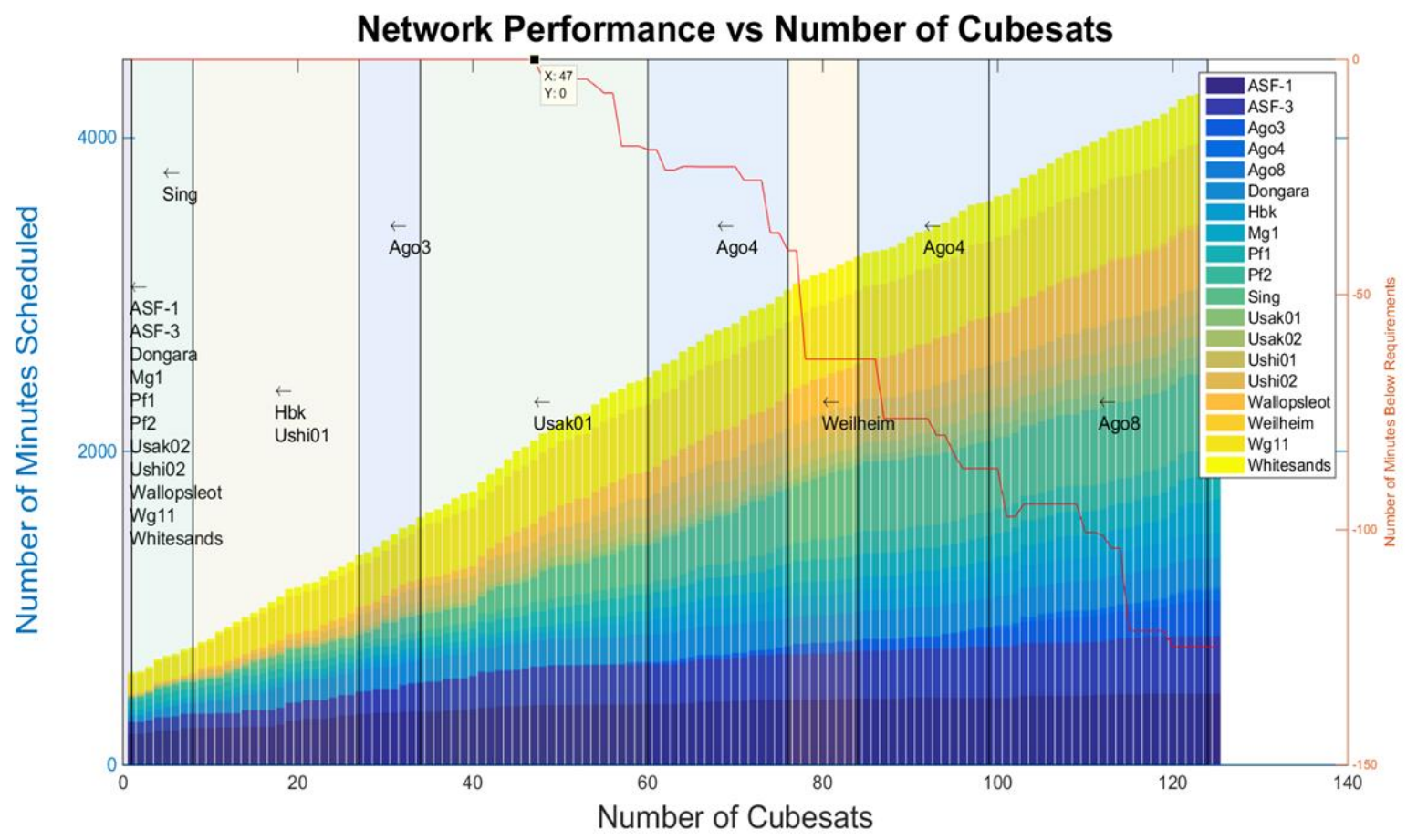

Figure 4. NEN Performance Versus Number of CubeSats.

Table 2. NEN CubeSat Capacity Modeling Assumptions.

\begin{tabular}{|l|l|l|}
\hline Assumption & Values & Importance \\
\hline CubeSat Orbit Altitude & $75 \%$ at $400 \mathrm{~km}$ and $25 \%$ at $700 \mathrm{~km}$ & Medium \\
\hline CubeSat Orbit Inclination & $25 \%$ at $28.5,50 \%$ at $53,25 \%$ at 98 & High \\
\hline Network Contact Time & Between 30 to 50 minutes scheduled & High \\
\hline Ground Network & NASA and Commercial Sites & High \\
\hline Other Users & NASA User Set & High \\
\hline Cost Considerations & None & High \\
\hline
\end{tabular}

Some key findings from the the analysis are as follows:

1. The NEN has the most difficulty supporting equatorial CubeSat users.

2. The NEN and its commercial partners have additional capacity to support ISS and Polar CubeSats. It is probable that interference between satellites will be the most limiting factor in the polar regions regardless of the number of sites and antennas constructed. Links to one site, such as Prudhoe Bay, cause interference to operations at multiple other sites (such as Fairbanks and Svalbard from Prudhoe). Growth and distribution in mid and lower latitude sites might be more effective at adding capacity and reducing latency.

3. If it is possible to control the orbit and number of contacts for each CubeSat mission, then the number of CubeSats the NEN can support could be maximized (i.e. reduce the probability for simultaneous contacts at a ground station). 
4. Network operational costs to the NEN and equatorial capacity could be improved with the addition of lower latitude stations to the NEN.

\section{B. Exploration Mission-1 (EM-1) and Future Exploration CubeSats}

NEN offers high gain ground system solutions for EM-1 and future exploration CubeSat missions with assets around the globe including NASA NEN and NEN commercial ground systems. Also the SN can be utilized for any S and Ka-band exploration CubeSat missions in the early phase of their trajectory. The first flight of NASA's new rocket, the Space Launch System (SLS), will carry 13 CubeSats to test innovative ideas along with EM-1 in 2018. See Figure 5, EM-1 Secondary Payloads. NASA plans to launch 13 CubeSats with every SLS launch, with CubeSats being released after the translunar injection (TLI) burn. After the EM-2 launch planned for 2023, it is anticipated that the SLS launch rate will increase to one/year, and in future years, may increase to two/year for the Mars campaign. NASA's mission to Europa, a potentially life-supporting moon of Jupiter, is expected to launch on SLS.

These small satellite secondary payloads will carry science and technology investigations to help pave the way for future human exploration in deep space, including the journey to Mars. SLS' first flight, referred to as EM-1, is providing the rare opportunity for these small experiments to reach deep space destinations, as most launch opportunities for CubeSats are limited to low-Earth orbit.

The Space Launch System (SLS) and Orion spacecraft

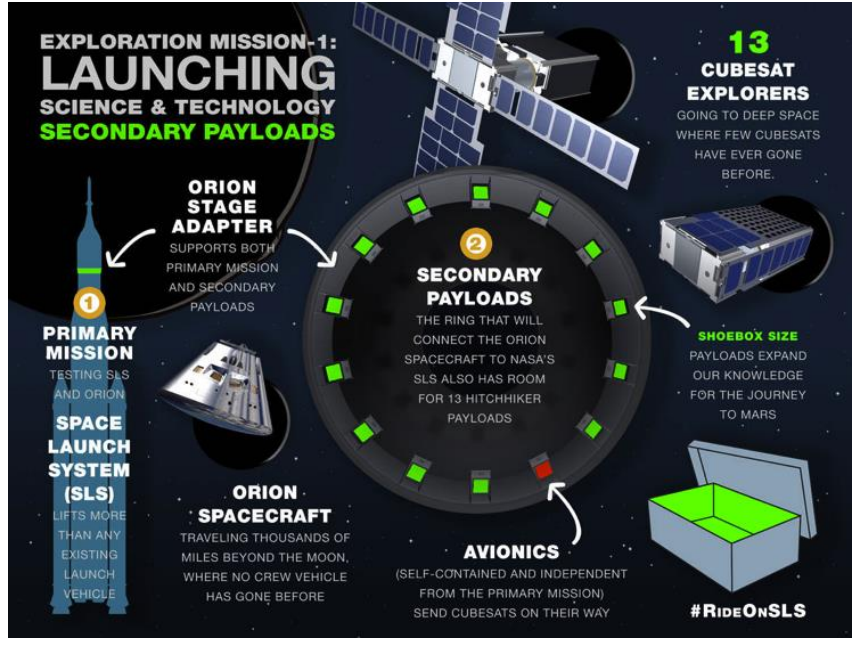

Figure 5. EM-1 Secondary Payloads, see http://www.nasa.gov/launching-science-andtechnology/multimedia.html?id=378536.

will not only take people on the most distant journeys to date but also open new frontiers for science and technology missions to deep space destinations. See https://www.nasa.gov/press-release/nasa-space-launch-system-s-first-flightto-send-small-sci-tech-satellites-into-space.

Several of the EM-1 CubeSat missions propose to use the IRIS X-band radio with four X-band patch antennas, two for receive and two for transmit. The IRIS Version 2 (V2) is a CubeSat/SmallSat compatible transponder developed by the Jet Propulsion Laboratory (JPL) as a low volume and mass, lower power and cost, software/ firmware defined telecommunications subsystem for deep space, see http://www.jpl.nasa.gov/cubesat/missions/iris.php. It's features include $0.5 \mathrm{U}$ volume, $1.1 \mathrm{~kg}$ mass, $26 \mathrm{~W}$ DC power consumption when fully transponding at $5 \mathrm{~W}$ radio frequency output (8 W DC input for receive only), and interoperability with NASA's Deep Space Network (DSN) at $\mathrm{X}$-Band frequencies (7.2 GHz uplink, $8.4 \mathrm{GHz}$ downlink) for command, telemetry, and navigation. The IRIS radio can support up to $256 \mathrm{kbps}$. It uses a hardware slice architecture and reconfigurable software and firmware enabling extension and adaptation to new capabilities. Among those now planned are: Radio Science support (atmospheric and media measurements and occultations, gravity fields, radars, and radiometers), additional frequency bands (Ka-, S-, and UHF-), Disruption/Delay Tolerant Networking (DTN), and proximity operations (at other planets such as Mars). Figure 6 shows the IRIS radio.

NASA NEN is considering adding X-band uplink capability to it's current NASA NEN stations and with this upgrade EM1, EM2 and future CubeSat missions using X-band uplink radios (e.g. IRIS) can be supported beyond early orbit trajectory phase. 
NASA NEN with Commercial and Academic Partner Ground Systems may address ground system needs for L1/L2, and Lunar CubeSat missions. NEN offers high gain large ground systems that are roughly 120 degrees apart around the earth for full coverage of L1/L2 and Lunar missions. A proposed network with the X-band upgrade may include WGS, ASF, MGS, WS1, APL, Morehead State University $21 \mathrm{~m}$ ground system, University of Michigan 26m ground system in the US, a Weilheim $18 \mathrm{~m}$ in Germany, and a USN $13 \mathrm{~m}$ in Australia. Adding X-band uplink to these ground systems would allow for CubeSats to use the IRIS radio in near earth orbits. Adding large commercial apertures to NEN, will enable better

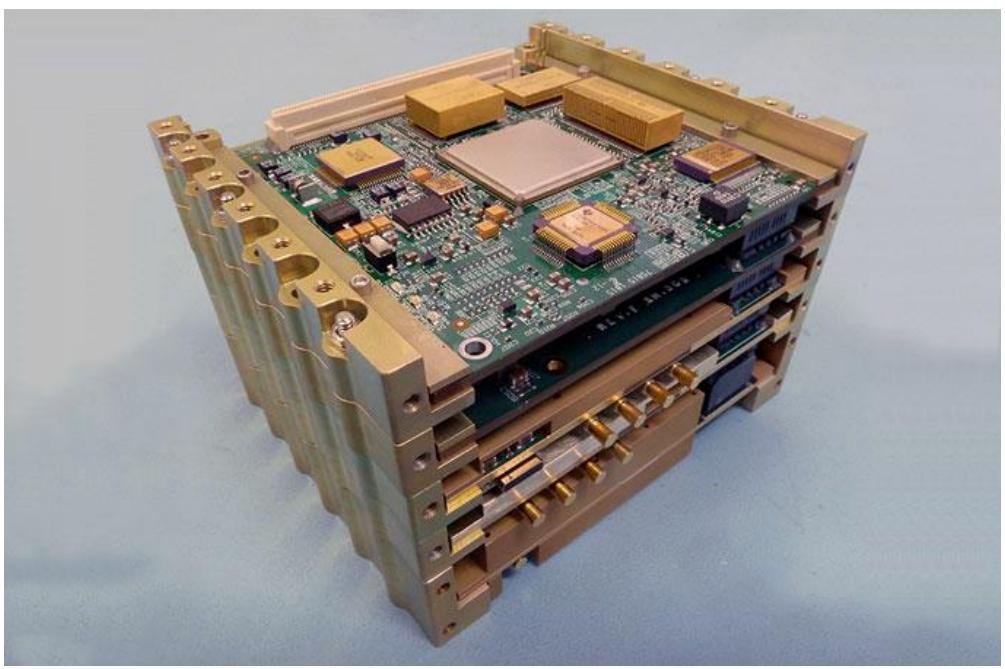

Figure 6. IRIS X-band Radio. support for CubeSat and traditional non-CubeSat Lunar and L1/L2 missions.

\section{Capitalizing on Commercial Services/Academic Partnerships}

The NEN today successfully manages commercial services. As new commercial services are offered for the CubeSat community, the NEN intends on capitalizing on those services to offer the advantage of minimum and bulk pass buy cost reductions to the satellite community.

CubeSats, because of their limited size and power, may require large ground stations $(>11 \mathrm{~m})$ to support their data rate in LEO. CubeSats, and traditional non-CubeSat missions, in Lunar and L1/L2 orbits require large ground stations for reasonable data rates from those distances.

The NEN intends to study the addition of potential commercial service and Academic Partnership large apertures, to complement the existing worldwide fleet of $11 \mathrm{~m}$ class X/S-band antennas and the $18 \mathrm{~m} \mathrm{Ka} / \mathrm{S}$-band antenna in White Sands. Purchasing $18 \mathrm{~m}$ antennas could be quite expensive (>\$6M/aperture).

Business cases must be established for the addition of commercial/Academic Partnership apertures. Pass rate costs, required upgrades, existing capability and availability will be traded against potential benefits. One of the Academic Partners being considered is Morehead State University.

The Morehead State University Space Science Center operates a 21-Meter Space Tracking Antenna that is capable of providing telemetry, tracking, and command (TT\&C) services for a wide variety of space missions. The system is designed to operate efficiently over a variety of frequency bands ranging from UHF to Ka-band. See Table 3 and Figure 7 for Ground System specifications. Measured performance characteristics of the L-band, S-band, High CBand Ku-band system made in situ on the instrument are provided in Table 3. The G/T values are measured at various elevations and the system temperature is calculated at 40 degree elevation. The system was designed with appropriate gain, drive speeds and pointing and tracking precision to provide the capability to track LEO satellites in moderately to highly inclined orbits. The gain and RF sensitivity are appropriate to support a robust niche radio astronomy research program. The basic performance characteristics (aperture, dynamics, and radio frequency) are provided below for the currently operating frequency regimes ${ }^{3}$. 


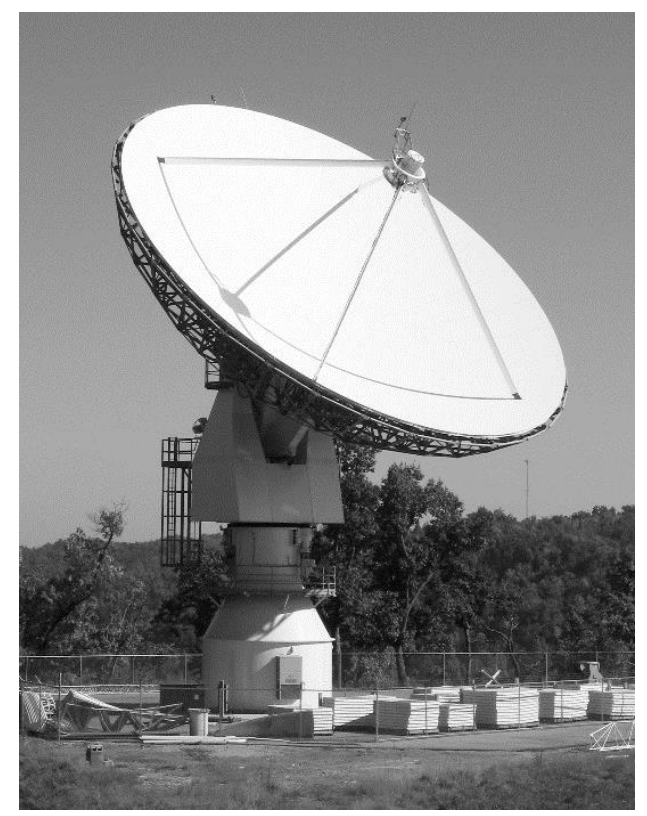

Figure 7. The Morehead State University Space Science Center 21-M Ground Station, Morehead, KY.

Table 3. Morehead State University 21-Meter Ground Station Performance Characteristics.

\begin{tabular}{|c|c|c|c|c|}
\hline \multirow{2}{*}{$\begin{array}{l}\text { Radio Frequency } \\
\text { Performance } \\
\text { Criterion }\end{array}$} & \multicolumn{4}{|c|}{ Performance Parameters } \\
\hline & L-Band & S-Band & $\begin{array}{l}\text { High C- } \\
\text { Band }\end{array}$ & Ku-Band \\
\hline Frequency & $1.40 \mathrm{GHz}$ & $\begin{array}{l}2.4-2.7 \\
\mathrm{GHz}\end{array}$ & 7.1-7.6 GHz & $11.2 \mathrm{GHz}$ \\
\hline Antenna Gain & $47.80 \mathrm{dBi}$ & $52.8 \mathrm{dBi}$ & $62.0 \mathrm{dBi}$ & $65.50 \mathrm{dBi}$ \\
\hline $\begin{array}{l}\text { System Temperature, } \\
\mathrm{T}_{\text {sys }}\end{array}$ & $83 \mathrm{~K}$ & $215 \mathrm{~K}$ & $215 \mathrm{~K}$ & $138 \mathrm{~K}$ \\
\hline $\mathrm{G} / \mathrm{T}$ at $5^{\circ}$ Elevation & $\begin{array}{l}28.6 \\
\mathrm{dBi} / \mathrm{K}\end{array}$ & $29.5 \mathrm{dBi} / \mathrm{K}$ & $38.7 \mathrm{dBi} / \mathrm{K}$ & $44.1 \mathrm{dBi} / \mathrm{K}$ \\
\hline HPBW & $0.62^{\circ}$ & $0.37^{\circ}$ & $0.13^{\circ}$ & $0.08^{\circ}$ \\
\hline
\end{tabular}

The 21-Meter is an extremely capable system, having pointing and tracking specifications capable of supporting space assets in a wide range of Earth orbits, sufficient aperture (and therefore gain) to support missions to the Moon and the inner solar system, and excellent surface accuracy (good enough to support Ku missions and potentially even Ka band missions)

Morehead State University 21-M Ground System could be upgraded to support Ka-band. Downconvertors and LNAs could be upgraded to enhance G/T value and for full NEN compatibility. Morehead State University 21-M Ground System can be easily utilized with the current NEN mission set with at least $10 \mathrm{~dB}$ margin and it can be also utililed by upcoming EM1 CubeSats and NEN Ka-band missions with necessary upgrades. Morehead uses the same HWCNTRL monitor and control software and similar Commercial off-the-shelf (COTS) control room equipment as other NEN sites. 


\section{NEN Ground System Performance Enhancements}

The receiver gain of the earth station to the total system noise temperature, Gain/Temperature (G/T), is a crucial performance characteristic of the ground station antenna systems. G/T is a good measure of the sensitivity of the receiving system and it is commonly used for link analysis. G/T measurements are basically the ratio of the antenna gain to the system noise temperature. To enhance ground system performance either the antenna gain could be increased or the system temperature could be decreased. The most effective way of decreasing the system temperature is utilizing a low noise amplifier (LNA) to diminish the system temperature right after the antenna.

The Deep Space Network (DSN) uses custom cryo-cooled LNAs and the X-band LNAs that they implement for the DSN are custom design. DSN uses Indium-Phosphide High Electron Mobility Transistor (HEMT) LNA chips and custom LNA topology to implement LNA modules. The X-band LNA modules typically operate at four to six degrees Kelvin noise temperature and are cryo-cooled using Sumitomo cryo-cooling systems. Currently NEN uses LNAs which have around 200 degrees Kelvin noise temperature. The cryo-cooling LNAs may be not cost effective and effeicient for NEN. However NEN can potentially consider upgrading the LNAs with less than 50 degrees Kelvin and ground systems can gain around $6 \mathrm{~dB}$ in the ground system performance. This could assist with high data rate CubeSats with limited power in low earth orbit and any mission out to Lunar and L1/L2 requiring additional performance.

\section{E. Power and Bandwidth Efficient Signal Techniques for CubeSat High Data Rate}

Due to the limited power and mass for CubeSat spacecraft, power and bandwidth efficient signal techniques such as Low-density parity-check code (LDPC) are recommended for use to achieve CubeSat high data rate requirements. As NASA earth science CubeSat mission channel bandwidth allocation at X-band is $375 \mathrm{MHz}$, high coding gain rate $1 / 2$ LDPC code is preferred over the low overhead rate 7/8 LDPC code for CubeSat high data rate missions which are in the order of no more than 100 to $200 \mathrm{Mbps}$. Bandwidth is not really a concern for a majority of earth science CubeSat missions at X-band. Maximizing the efficiency of RF power is the key to achieve higher data rate. Bandwidth is an issue due to interference. Higher order modulations ( 8 and 16 at least) could allow more missions to co-exist without overlap to increase usage of polar regions.

Rate $1 / 2$ LDPC code produces a $2.5 \mathrm{~dB}$ coding gain over conventional rate $1 / 2$ convolutional code while rate $7 / 8$ LDPC coding gain is only $0.5 \mathrm{~dB}$ better. High order modulation like 8 Phase Shift Keying (PSK) is not really necessary to be used for CubeSat missions in the X-band $375 \mathrm{MHz}$ channel.

The channel bandwidth allocation for NASA CubeSat missions at S-band is only $5 \mathrm{MHz}$. High rate LDPC code with low overhead to increase bandwidth efficiency is recommended for CubeSat NEN communication links. High order modulations like 8 PSK will be considered to increase the CubeSat data rate in the S-band $5 \mathrm{MHz}$ channel. A study on the use of power and bandwidth efficient modulation and coding schemes for NEN CubeSat communication links at S and X-band for increased data rate and spectral efficiency is being conducted. CCSDS and DVB-S2 signal schemes including the LDPC family will be considered in the study. Based on recommendation of the study, the Cortex receivers at NEN station may be enhanced to support future CubeSat high data rate missions.

The vendor Tethers Unlimited Inc (TUI) S and X-band Software Defined Radios (SDR) support high order modulation and Consultative Committee for Space Data Systems (CCSDS) and Digital Video Broadcasting - Satellite - Second Generation (DVB-S2) LDPC coding schemes. The compatibility tests to be conductd at GSFC Compatibility Test Lab (CTL) and Wallops station will demonstrate the performance of these signal schemes for the support of future CubeSat high data rate missions.

High data rate allows the delivery of data volume with less coverage time, hence, reduces the number of passes required. This has the advantage of lessening the load on the network and lowering the potential cost to the mission. Higher data rates with shorter pass times could contribute to controlled sequencing between missions to help alleviate interference events, or allow a spacecraft to stay silent during a conjunction event with another spacecraft and possibly still have time to complete a link transaction after conjunction criteria have passed.

\section{NEN and SN Compatible Flight Radios and Antennas}

There is a need for a standard, robust and low cost CubeSat/SmallSat communication architecture for high data rate science missions. This takes advantage of both ground and CubeSat/SmallSat communication systems performance enhancements by utilizing higher data rate communication systems. The most critical components of a CubeSat communication systrems are radios and antennas. Compact, power efficient, reliable radios and antennas will enable new mission classes or reduce the cost, schedules, and risk of current CubeSat mission design methodologies. Table 4 presents current state of the art UHF-, S-, X- and Ka-band radios.

American Institute of Aeronautics and Astronautics 
One of the key challenges of CubeSat communication systems is finding NASA communication infratructrure compatible radios. To address this challenge, currently NASA GSFC is working with different radio vendors on NEN/SN compatibility. Table 4 shows NASA Network Compatibility however this table presents just the vendor claims. To be able to be considered as a truly NASA NEN and SN Compatible communication systems without flight heritage, it is recommended that the radio go through the development of a Radio Frequency Internace Control Document (RFICD), compatibility test and end-to-end. Some of the the radios have been already tested and some of them them are in the process of being tested.

Table 4. Selected CubeSat Radios.

\begin{tabular}{|c|c|c|c|c|c|c|c|}
\hline Freq. & $\begin{array}{l}\text { Transceiver } \\
\text { Name/Vendor }\end{array}$ & Size (cm) & $\begin{array}{l}\text { Mass } \\
(\mathrm{g})\end{array}$ & $\begin{array}{l}\text { Flight } \\
\text { Heritage }\end{array}$ & $\begin{array}{l}\text { Max. Data } \\
\text { Rate }\end{array}$ & Modulation/FEC & $\begin{array}{c}\text { NASA } \\
\text { Network } \\
\text { Compatibility }\end{array}$ \\
\hline \multirow[t]{2}{*}{$\begin{array}{l}\text { UHF- } \\
\text { band }\end{array}$} & L3 Cadet UHF Tx & $6.9 \times 6.9 \times 1.3$ & 215 & $\begin{array}{l}\text { DICE, } \\
\text { MicroMAS, } \\
\text { CeREs }\end{array}$ & 2.6 Mbps & BPSK & None \\
\hline & $\begin{array}{r}\text { ISIS Transceiver } \\
\text { (ITRX) }\end{array}$ & $9.6 \times 9.0 \times 1.5$ & 85 & Delfi-n3Xt & $\begin{array}{r}1.2 \mathrm{Kbps} \\
\text { Downlink/9.6 } \\
\text { Kbps Uplink }\end{array}$ & Rx AFSK/Tx BPSK & None \\
\hline \multirow[t]{7}{*}{ S-band } & Innoflight SCR-100 & $8.2 \times 8.2 \times 3.2$ & 300 & Sense NanoSat & $4.5 \mathrm{Mbps}$ & $\begin{array}{r}\text { BPSK,QPSK,OQPSK } \\
\text { GMSK,FM/PCM FEC: } \\
\text { Conv. and R/S }\end{array}$ & NEN, SN, DSN \\
\hline & $\begin{array}{r}\text { Tethers Unlimited } \\
\text { SWIFT-SLX }\end{array}$ & $10 \times 10 \times 3.5$ & 380 & None & 15 Mbps & BPSK & NEN,SN,DSN \\
\hline & \multirow[t]{2}{*}{$\begin{array}{r}\text { L3 Cadet S-Band Tx } \\
\text { (CXS-1000) }\end{array}$} & \multirow[t]{2}{*}{$6.9 \times 6.9 \times 1.3$} & \multirow[t]{2}{*}{215} & \multirow[t]{2}{*}{ None } & \multirow[t]{2}{*}{6 Mbps } & BPSK, QPSK, SOQPSK, & \multirow[t]{2}{*}{ None } \\
\hline & & & & & & SGLS M/FSK & \\
\hline & $\begin{array}{r}\text { Clyde Space S-Band } \\
\text { TX (STX) }\end{array}$ & $9.6 \times 9.0 \times 1.6$ & $<80$ & UKube-1 & & & \\
\hline & $\begin{array}{r}\text { Nimitz Radio S-band } \\
\text { Tx/UHF Rx }\end{array}$ & $9 \times 9.6 \times 1.4$ & 500 & None & $\begin{array}{r}50 \text { Kbps } \\
\text { Downlink/1 } \\
\text { Mbps Uplink }\end{array}$ & $\begin{array}{r}\text { Uplink FSK, GFSK } \\
\text { Downlink BPSK }\end{array}$ & None \\
\hline & MHX-2420 & 8.9X5.3X1.8 & 75 & RAX & $\begin{array}{r}230 \text { Kbps } \\
\text { Downlink/115 } \\
\text { Kbps Uplink }\end{array}$ & FSK & Partially NEN \\
\hline \multirow[t]{5}{*}{$\begin{array}{l}\text { X- } \\
\text { band }\end{array}$} & $\begin{array}{r}\text { LASP/GSFC X-band } \\
\text { Radio }\end{array}$ & $9.8 \times 9 \times 2$ & 500 & None & $\begin{array}{r}12.5 \text { Mbps } \\
\text { Downlink/50 } \\
\text { Kbps Uplink }\end{array}$ & $\begin{array}{r}\text { BPSK/OQPSK R/S and } \\
\text { Conv. }\end{array}$ & NEN \\
\hline & $\begin{array}{r}\text { Syrlinks/X-band } \\
\text { Transmitter }\end{array}$ & $9 \times 9.6 \times 2.4$ & 225 & None & 5 Mbps & $\begin{array}{r}\text { BPSK/OQPSK R/S and } \\
\text { Conv. }\end{array}$ & NEN \\
\hline & Marshall X-band Tx & $10.8 \times 10.8 \times 7.6$ & $<1000$ & FASTSat2 & $\begin{array}{r}150 \text { Mbps } \\
\text { Downlink/50 } \\
\text { Kbps Uplink }\end{array}$ & $\begin{array}{rr}\text { BPSK/OQPSK } & \text { LDPC } \\
7 / 8\end{array}$ & NEN \\
\hline & $\begin{array}{r}\text { Tethers Unlimited } \\
\text { SWIFT-XTS }\end{array}$ & $\begin{array}{l}8.6 \times 4.5 \\
(0.375 U)\end{array}$ & 500 & None & 100 Mbps & $\{8,16 A, 32 A\} P S K$ & NEN,SN,DSN \\
\hline & JPL /Iris Transponder & $0.4 \mathrm{U}$ & 400 & INSPIRE & $\begin{array}{r}62.5 \mathrm{Kbps} \\
\text { Donwlink/1 } \\
\text { Kbps Uplink }\end{array}$ & $\begin{array}{r}\text { BPSK bit sync, CCSDS } \\
\text { frame size }\end{array}$ & DSN \\
\hline \multirow[t]{2}{*}{$\begin{array}{l}\text { Ka- } \\
\text { band }\end{array}$} & Ames Ka-band Tx & $18 \times 10 \times 8.5$ & 820 & None & $125 \mathrm{Mbps}$ & $\begin{array}{r}\text { \{Q,8,16A,32A\}PSK, DVB- } \\
\text { S2, CSSDS, LDPC } \\
\text { Concatenated with BCH }\end{array}$ & NEN,SN,DSN \\
\hline & $\begin{array}{r}\text { Tethers Unlimited } \\
\text { SWIFT-KTX }\end{array}$ & $\begin{array}{l}8.6 \times 4.5 \\
(0.375 U)\end{array}$ & 500 & None & $100 \mathrm{Mbps}$ & $\begin{array}{r}\{Q, 8,16 A, 32 A\} P S K, \text { DVB- } \\
\text { S2, CSSDS }\end{array}$ & NEN,SN,DSN \\
\hline
\end{tabular}


CubeSat antennas are really critical components of CubeSats considering power, pointing and real estate limitations of CubeSat missions. CubeSat antennas manily operate at UHF, S and X-band. Some cubesats are starting to consider Ka-band systems. The below list presents CubeSat antenna types at different operating frequencies.

- UHF-band

- Dipole- Omni Coverage

- Turnstile-Hemispherical Coverage

- S-band

- Patches- Omni Coverage

- Deployable reflector or Patch Array- High Gain

- X-band

- Patches- Omni Coverage

- Deployable reflector or Patch Array- High Gain

- Ka-band
- Horn- Medium Gain
○ Deployable reflector - High Gain

Table 5 presents selected COTS CubeSat antennas.

Table 5. UHF-, S-, X- and Ka-band COTS CubeSat Antennas.

\begin{tabular}{|c|c|c|c|c|c|}
\hline Antenna Vendor - Name & Frequency & $\begin{array}{l}\text { Antenna Gain } \\
\text { (dBi) }\end{array}$ & TRL & Dimensions & Mass \\
\hline ISIS Deployable & UHF & 0 & 9 & $30 \mathrm{~cm}$ & $100 \mathrm{~g}$ \\
\hline Haigh Farr - S-band Patch & $\mathrm{S}$ & $2 \mathrm{~dB}$ & 9 & $(94 \times 76 \times 4) \mathrm{mm}$ & $62 \mathrm{~g}$ \\
\hline $\begin{array}{l}\text { Antenna Development Corp - } \\
\text { S-band Patch }\end{array}$ & $\mathrm{S}$ & $2 \mathrm{~dB}$ & 9 & $(4 \times 4 \times 0.25)^{\prime \prime}$ & $115 \mathrm{~g}$ \\
\hline $\begin{array}{l}\text { Antenna Development Corp - } \\
\text { X-band Patch }\end{array}$ & $x$ & $4 \mathrm{~dB}$ & 9 & $(1.85 \times 1.85 \times 0.55)^{\prime \prime}$ & $300 \mathrm{~g}$ \\
\hline $\begin{array}{l}\text { BDS Phantom Works } \\
\text { Deployable High Gain S-band } \\
\text { Antenna }\end{array}$ & $\mathrm{S}$ & 18 & 9 & $50 \mathrm{~cm}$ & $1000 \mathrm{~g}$ \\
\hline $\begin{array}{l}\text { BDS Phantom Works } \\
\text { Deployable High Gain X-band } \\
\text { Antenna }\end{array}$ & $\mathrm{x}$ & 25 & 9 & $50 \mathrm{~cm}$ & $1000 \mathrm{~g}$ \\
\hline Canopus Systems Horn & $\mathrm{Ka}$ & 25 & 9 & $18 \mathrm{~cm}$ & $820 \mathrm{~g}$ \\
\hline
\end{tabular}

Figure 8 shows some selected CubeSat antennas. 


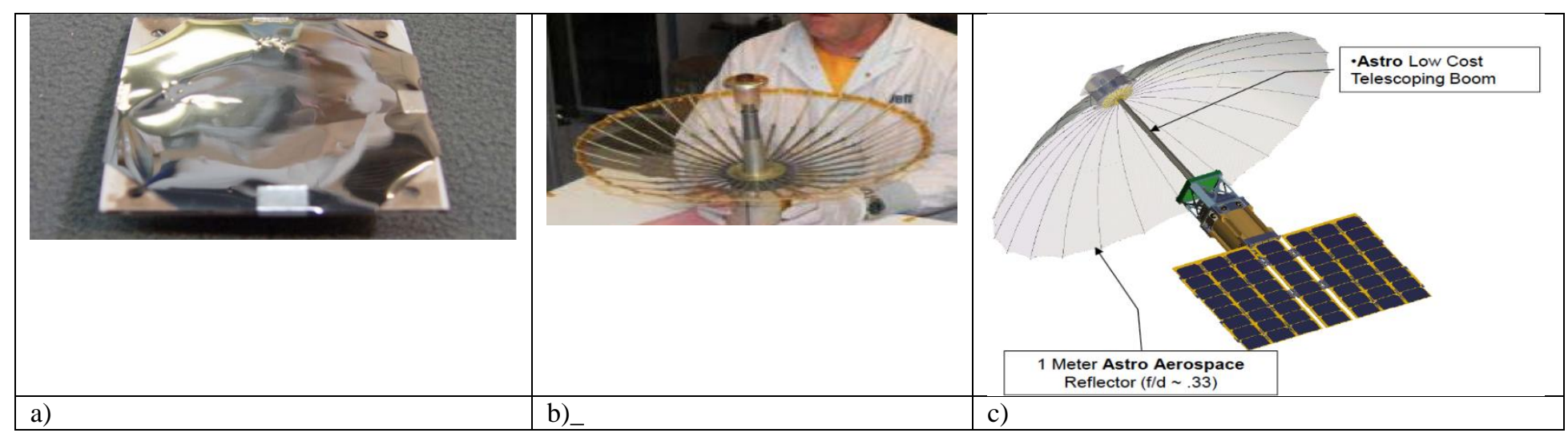

Figure 8. a) Ant Dev Corp X-band Patch Array b) USC's S- and X-band Deployable Reflector c)Astro Aerospace.

Utah State University (USU) and NASA GSFC are collaborating in the development of an Integrated Solar-Panel Antenna Array for CubeSats. USU has demonstrated that optically transparent antennas can be printed with conductive ink on optically transparent substrates, and integrated with solar arrays ${ }^{4,5,6,7}$. The Integrated Solar-Panel Antenna Array for CubeSats (ISAAC) is a high gain, X-band antenna array that is integrated with the solar panels of a CubeSat, see Figure 9. The antenna designs are modular designs that are independent from the solar cells, and therefore allow offthe-shelf components. In addition, the antennas do not compete for valuable surface real estate with solar cells. ISAAC will suit a multi-unit $(\geq 3 \mathrm{U})$ CubeSat that has sufficient area for solar panels, hence the antennas, or a Cubesat with deployed panels. The targeted application of ISAAC is for NEN, however, the design can be conveniently scaled to SN and Deep Space Network (DSN) frequencies.

This research team is examining two type of elements, cross dipole and loop which can provide sufficient phase range for the array. The study is examining the element performance for different array lattice sizes such as half wavelength and sub-wavelength. Also, they are investigating the required minimum cover glass height for each kind of element so that the reflectarray can function effectively.

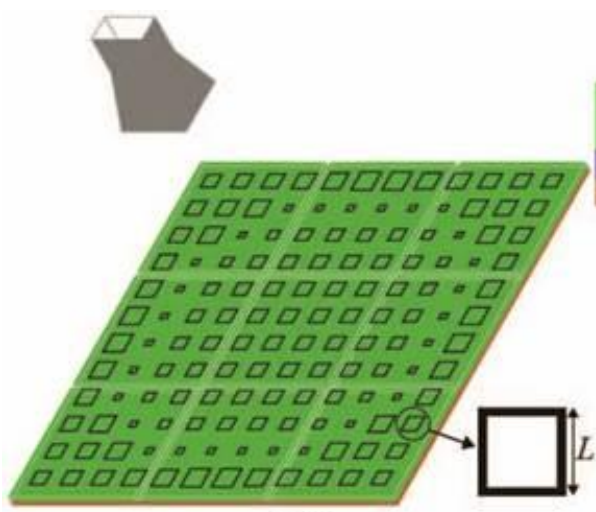

(a)

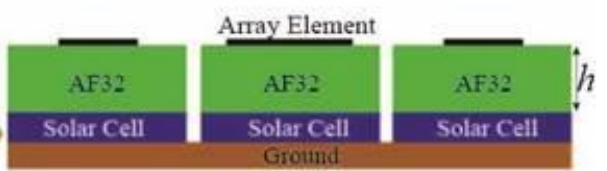

(b)

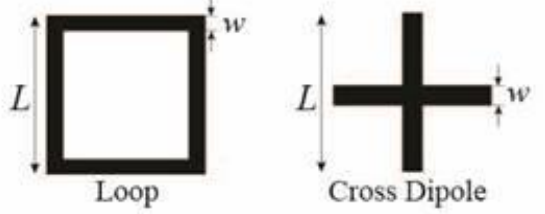

(c)

\section{Space Science}

Earth exploration satellites are granted $8025-8400 \mathrm{MHz}$ of the Xband spectrum or a 375 $\mathrm{MHz}$ bandwidth, which to date has not been a limiting factor for data rates for a majority of earth science missions. Astrophysics, Heliophysics, and Planetary (Space Science) missions are limited to 8450-8500, and with a further limitation of only

Elements.

$10 \mathrm{MHz}$ of bandwidth per mission. This has driven some missions to Ka Band for higher data rates over a larger bandwidth allocation (e.g. Solar Dynamics Observatory (SDO), the James Webb Space Telescope (JWST))

A study has been conducted to determine the maximum achievable data rate in the $\mathrm{X}$-band $10 \mathrm{MHz}$ bandwidth channel without violating power flux density limits. This study applies to both CubeSat and non-CubeSat traditional missions. Bandwidth efficient modulation and coding techniques such as Offset Quadrature Phase Shift Keying (OQPSK), 8 Phase Shift Keying (PSK), 16 asymmetric phase-shift keying (APSK), 32 APSK, 16 Quadrature Amplitude Modulation (QAM) and Rate 7/8 LDPC code were engaged in the study. Simulations have been performed

American Institute of Aeronautics and Astronautics 
to determine the Bit Error Rate (BER) performance of these modulation schemes with rate 7/8 LDPC and a variety of distortion scenarios were considered.

A MatLab/SimuLink NEN X-band $10 \mathrm{MHz}$ NEN end-to-end simulation model was developed to support the study. Figure 9 illustrates the MatLab/SimLink model for a CubeSat with a data rate of $28 \mathrm{Mbps}$, with rate 7/8 LDPC coded 16 APSK X-band over a $10 \mathrm{MHz}$ bandwidth for NEN. It assumes that the CubeSat transmit power is $2 \mathrm{~W}$ and antenna gain is $6 \mathrm{dBi}$ at an altitude of $500 \mathrm{~km}$ and the supporting station is a NEN X-band 11-meter in Alaska.

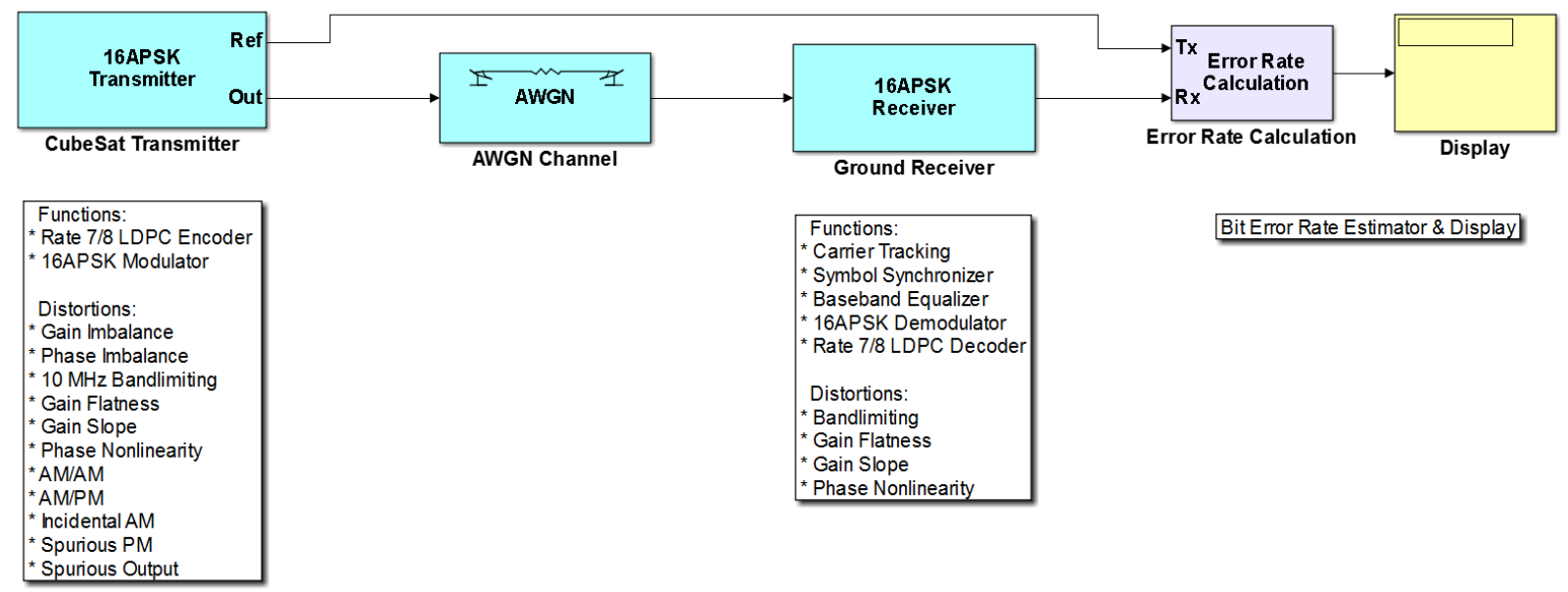

Figure 10. MatLab/SimuLink NEN X-band 10 MHz NEN End-to-End Simulation Model.

A summary of trade results in shown in Table 6.

American Institute of Aeronautics and Astronautics 
Table 6. Modulation and Data Rate Results.

\begin{tabular}{|c|c|c|c|c|}
\hline Modulation & Coding & $\begin{array}{l}\text { Max } \\
\text { Data } \\
\text { Rate }\end{array}$ & $\begin{array}{l}\text { Implementation } \\
\text { loss at 10-5 BER }\end{array}$ & Comment \\
\hline OQPSK & $\begin{array}{l}7 / 8 \\
\text { LDPC }\end{array}$ & $16 \mathrm{Mbps}$ & $3.6 \mathrm{~dB}$ & $\begin{array}{l}\text { There is significant positive link margin assuming a } \\
\text { CubeSat equivalent isotropically radiated power (EIRP) } \\
\text { with } 8.0 \mathrm{dBW} \text { ( } 2 \text { Watt TX Power). }\end{array}$ \\
\hline 8PSK & $\begin{array}{l}7 / 8 \\
\mathrm{LDPC}\end{array}$ & $\begin{array}{l}23.6 \\
\text { Mbps }\end{array}$ & $4.1 \mathrm{~dB}$ & $\begin{array}{l}\text { For the } 6 \mathrm{~dB} \text { implementation loss case, it was assumed } \\
\text { that the CubeSat transmitter distortions are the same as } \\
\text { defined in the Space Network Users Guide (SNUG). S- } \\
\text { band Single Access Return (SSAR) user distortions were } \\
\text { used except with a lower Power Amplifier (PA) } \\
\text { nonlinearity. For the } 5 \mathrm{~dB} \text { case, it was assumed the } \\
\text { CubeSat transmitter had less distortions than the SNUG } \\
\text { defined SSAR user distortions amount and lower PA } \\
\text { nonlinearity. }\end{array}$ \\
\hline \multirow[t]{2}{*}{16 APSK } & \multirow[t]{2}{*}{$\begin{array}{l}7 / 8 \\
\text { LDPC }\end{array}$} & \multirow[t]{2}{*}{$28 \mathrm{Mbps}$} & $>6 \mathrm{~dB}$ & $\begin{array}{l}\text { For the } 6 \mathrm{~dB} \text { case, same as in note } 2 \text {. For the } 5 \mathrm{~dB} \text { case, it } \\
\text { was assumed the CubeSat transmitter had much less } \\
\text { distortions than the SNUG defined SSAR user } \\
\text { distortions amount and lower PA nonlinearity. }\end{array}$ \\
\hline & & & $\sim 5 \mathrm{~dB}$ & \\
\hline \multirow[t]{2}{*}{32 APSK } & \multirow[t]{2}{*}{$\begin{array}{l}7 / 8 \\
\text { LDPC }\end{array}$} & \multirow[t]{2}{*}{$30 \mathrm{Mbps}$} & $>6 \mathrm{~dB}$ & $\begin{array}{l}32 \text { APSK should not be considered because it has } \\
\text { minimum benefits on data rate. }\end{array}$ \\
\hline & & & $\sim 5 \mathrm{~dB}$ & \\
\hline \multirow[t]{2}{*}{16 QAM } & \multirow[t]{2}{*}{$\begin{array}{l}7 / 8 \\
\text { LDPC }\end{array}$} & \multirow[t]{2}{*}{$28 \mathrm{Mbps}$} & $>6 \mathrm{~dB}$ & $\begin{array}{l}\text { Considering } 16 \text { APSK can achieve the same data rate } \\
\text { with less stringent constraints, } 16 \text { QAM should not be } \\
\text { considered. }\end{array}$ \\
\hline & & & $\sim 5 \mathrm{~dB}$ & \\
\hline
\end{tabular}

The conclusions of this particular study are as follows. High order modulation schemes are susceptible to transmitter linear distortions and are very susceptible to nonlinearity. The CubeSat transmitter must have stringent distortion constraints (especially the nonlinearity constraint) in order to use high order modulation schemes. Among high order modulation schemes evaluated in this study, 16 APSK is feasible since it only requires the CubeSat to have a quasi-linear power amplifier, which can be done via pre-distortion compensation. 16 APSK and 16 QAM require very stringent constraints on the CubeSat transmitter in order to close the link with a reasonable amount of link margin. 32 APSK does not close the link even with very stringent constraints on the CubeSat transmitter. 32 APSK barely closes the link even if distortion constraints on the ground terminal are increased as well. 32 APSK is also at a relatively low Technology Readiness Level (TRL) compared to the other modulation schemes.

The Cortex receiver at NEN Stations supports high order modulation such as 8 PSK, 16 APSK and a variety of LDPC coding schemes. A compatibility test with the Cortex receiver and the vendor Tethers Unlimited Inc (TUI) Xband SDR radio to validate the study results is planned for the summer of 2016.

\section{Ka-Band}

A study has been performed to determine the achievable data rates at Ka-band with ground antennas ranging from the small portable $1.2 \mathrm{~m} / 2.4 \mathrm{~m}$ to apertures $5.4 \mathrm{M}, 7.3 \mathrm{M}, 11 \mathrm{M}$, and $18 \mathrm{M}$, for Low Earth Orbit (LEO) to Lunar CubeSat missions. Results of the study are summarized in Table 7. For the analysis, the 18M station is at White Sands Complex (WSC) and the other antenna appertures are assumed at Alaska Facility (ASF). There are two kinds of CubeSat Kaband flight systems used for the analysis. One is a Commerical Off-the-shelf (COTS) SDR Ka-band transceiver with a 2W PA and an earth coverage antenna of $4 \mathrm{dBi}$ gain. The second is a Ka-band DVB-S2 transmitter system with a high gain horn antenna of $23 \mathrm{dBi}$ and a $0.7 \mathrm{~W}$ PA for the LEO CubeSat mission and the same antenna but with a $2 \mathrm{~W}$ 
PA for the Lunar CubeSat mission. Modulation is Quadrature Phase Shift Keying (QPSK) and with rate 1/2 LDPC coding. Rain Availability is assumed $99 \%$ at ASF and $95 \%$ at WSC at 10 degrees elevation angle.

Table 7. Achievable Data Rate at Ka-Band.

\begin{tabular}{|c|c|c|c|}
\hline Ground Antenna & LEO Data Rate QPSK* & $\begin{array}{c}\text { Data Rate LEO DVB-S2 } \\
\text { *** }\end{array}$ & \begin{tabular}{c} 
Data Rate Lunar**** \\
\hline ASF $1.2 \mathrm{~m}$
\end{tabular} \\
\hline ASF $2.4 \mathrm{~m}$ & $477.5 \mathrm{kbps}$ & $16.943 \mathrm{Mbps}$ & - \\
\hline ASF $5.4 \mathrm{~m}$ & $1.574 \mathrm{Mbps}$ & $55.847 \mathrm{Mbps}$ & -- \\
\hline ASF 7.3 m & $4.3 \mathrm{Mbps}$ & $153.4 \mathrm{Mbps}$ & $10.6 \mathrm{kbps}$ \\
\hline ASF $11 \mathrm{~m}$ & $6.6 \mathrm{Mbps}$ & $233.2 \mathrm{Mbps}$ & $16.1 \mathrm{kbps}$ \\
\hline WSC $18 \mathrm{~m}$ & $25.2 \mathrm{Mbps}$ & $892.9 \mathrm{Mbps}$ & $61.5 \mathrm{kbps}$ \\
\hline & $257.5 \mathrm{Mbps}$ & $1125 \mathrm{Mbps}$ & $629.5 \mathrm{kbps}$ \\
\hline
\end{tabular}

* LEO $(625 \mathrm{~km})$ COTS QPSK Transceiver, 2W PA, earth coverage antenna of $4 \mathrm{dBi}$ gain

** LEO (625 km) DVB-S2 Transceiver, $0.7 \mathrm{~W}$ PA, horn antenna of $23 \mathrm{dBi}$ gain

*** Lunar (400,000 km) DVB-S2 Transceiver, 2 W PA, horn antenna of 23 dBi gain

\section{CubeSat Constellations}

CubeSat constellations are designed to optimize coverage over specific areas or improve global revisit times to fulfill the mission purpose. There is growing interest among the science community in using constellation of CubeSats to enhance observations for earth and space science. The CubeSat constellation communication concepts with respect to NEN/SN contains several scenarios. This includes CubeSat swarms, daughter ship/mother ship constellations, NEN S- and X-band direct-to-ground links, Tracking and Data Relay Satellite System (TDRSS) Multiple Access (MA) array and Single Access modes.

A CubeSat constellation may involve numerous CubeSats in the constellation, (e.g., tens or hundreds). Each CubeSat is typically identical from a communication perspective. One CubeSat may be mother ship-capable while the others may be subordinate (i.e. daughter ships), however, multiple CubeSats may have the ability to fulfill the role of a mother ship.

The mother ship may be a store-forward relay which is capable of transmit/receive between the subordinate CubeSats and may downlink the science data to the ground either through a NEN direct to ground link at X-band or through a TDRSS Ka-band Single Access (KaSA) service. Patch antennas may be used between the mother ship and the subordinate CubeSats for the inter-satellite communication link to provide the required omni-coverage using an accurate attitude pointing system for each daughter ship. Earth coverage antennas in X-band with uniform gain may be used for communication between the mother ship and NEN ground stations for high data rate downlink.

Given the limited CubeSat transmit power, communication with TDRSS KaSA mode requires a steering antenna or inflatable/phased array antenna on board the mother ship for a high data rate downlink. In case of emergency or other reasons, the CubeSat communication may take place directly through TDRSS MA array mode or NEN direct to ground station mode.

\section{A. Constellation Coded Division Multiple Access (CDMA) Signal Trades Study}

A CDMA signal trade study has been conducted for CubeSat mother/daughter constellation inter-satellite link communications. The study was intented to solve for the most appropriate CDMA signal characteristics/design and CubeSat orbit for mother/daughter constellation inter-satellite link communications that would be able to downlink an adequate daily data volume to the ground. Many Cubesats use GPS for position identification. The study assumed a mother to daughter forward link that is used to command the daughter to downlink science data to the mother and to provide mother position information to daughter. With a unique assigned Psuedo Noise (PN) code, there is no need to perform frequency management for the CubeSat inter-satellite CDMA link. Navigation for constellations of CubeSats may require additional techniques beyond GPS for more accurate position determination and formation flying.

If CubeSats are deployed out of the launch vehicle on a strict timeline and possess the ability to stationkeep and maintain a formation, then the following data is feasible. As the number of daughter CubeSats increases, the daily data volume rises linearly. The study assumes the constellation contains 20 daughters with one mother ship Cubesat and the slant range between daughter and mother is $100 \mathrm{~km}$. The CubeSat communication system contains a $2 \mathrm{~W}$ Power Amplifier (PA), and a patch antenna of zero dBi gain. The mother ship CubeSat G/T is $27 \mathrm{~dB} / \mathrm{K}$ with a 50\%

American Institute of Aeronautics and Astronautics 
daughter ship communication duty cycle. Results of the study for total daily data volume with the slant range of 100 $\mathrm{km}$ in the daughter/mother constellation orbit are shown in Table 8.

Table 8. Data Volume Versus Coding.

\begin{tabular}{|c|c|c|c|c|}
\hline Parameter & \multicolumn{4}{|l|}{ Value } \\
\hline Slant range $(\mathrm{Km})$ & \multicolumn{4}{|l|}{100} \\
\hline Modulation & \multicolumn{4}{|l|}{ QPSK } \\
\hline Chip rate (Mcps) & \multicolumn{2}{|l|}{1} & \multicolumn{2}{|l|}{3} \\
\hline Coding & 1/2 LDPC & 7/8 LDPC & 1/2 LDPC & 7/8 LDPC \\
\hline $\begin{array}{l}\text { Theoretical Eb/No for 10- } \\
5 \text { BER (dB-Hz) }\end{array}$ & 1.75 & 3.85 & 1.75 & 3.85 \\
\hline Imp. Loss (dB) & 1.8 & 1.8 & 2.0 & 2.0 \\
\hline Margin (dB) & 2.0 & 2.0 & 2.0 & 2.0 \\
\hline $\begin{array}{l}\text { Max. achievable dara } \\
\text { rate with } 20 \text { simultaneous } \\
\text { daughter ships (Kbps) }\end{array}$ & 39.7 & 24.5 & 95.0 & 58.6 \\
\hline $\begin{array}{l}\text { Total data volume per } \\
\text { second }(\mathbf{K b})\end{array}$ & 397.0 & 245.0 & 950.0 & 586.0 \\
\hline $\begin{array}{l}\text { Total daily data volume } \\
\text { (Gb) }\end{array}$ & 34.3 & 21.1 & 82.1 & 50.6 \\
\hline
\end{tabular}

Based on the maximum achievable data rates, the total daily data volumes are $34.3 \mathrm{Gbits}, 21.1 \mathrm{Gbits}, 82.1 \mathrm{Gbits}$, 50.6 Gbits accordingly.

If CubeSats are deployed out of the launch vehicle on no strict timeline and with no ability to station keep after being deployed, then the following data rates are achievable. The study assumed the constellation contains 20 daughters with one mother CubeSat. A simulated CubeSat orbit for 14 days was used to support the analysis. The orbits are based upon all Cubesats being in typical CubeSat orbits, but unsynchronized with each other. Results of the study/analysis are shown in Tables 9 and 10.

Table 9. Data Volume Versus Slant Range for 1/2 LDPC.

\begin{tabular}{|c|c|c|c|c|c|c|}
\hline \multirow{3}{*}{$\begin{array}{c}\text { Max- } \\
\text { Supported } \\
\text { Mother-to- } \\
\text { Daughter } \\
\text { Slant } \\
\text { Range } \\
\text { (km) }\end{array}$} & \multirow{3}{*}{$\begin{array}{c}\text { Probability } \\
\text { That } \\
\text { Daughter } \\
\text { Cubesat Is } \\
\text { Within This } \\
\text { Slant Range }\end{array}$} & \multirow{3}{*}{$\begin{array}{l}\text { Maximum } \\
\text { Number of } \\
\text { Daughters } \\
\text { Within This } \\
\text { Slant Range }\end{array}$} & \multicolumn{2}{|c|}{$\begin{array}{l}\text { Maximum Achievable Data Rate } \\
\text { (per Daughter, Kbps) }\end{array}$} & \multicolumn{2}{|c|}{$\begin{array}{c}\text { Maximum Achievable Daily Data Volume } \\
\text { (per Daughter, Mb) }\end{array}$} \\
\hline & & & \multirow[t]{2}{*}{1 Daughter } & Max \# of Daughters & \multirow[t]{2}{*}{1 Daughter } & Max \# of Daughters \\
\hline & & & & $\begin{array}{l}\text { All effectively at Max- } \\
\text { Supported Slant } \\
\text { Range via Power } \\
\text { Control }\end{array}$ & & $\begin{array}{c}\text { All effectively at Max- } \\
\text { Supported Slant } \\
\text { Range via Power } \\
\text { Control }\end{array}$ \\
\hline 250 & $0 \sim 0.13 \%$ & 1 & 102.514 & 102.514 & $0 \sim 11.51$ & $0 \sim 11.51$ \\
\hline 1000 & $0.26 \sim 3.98 \%$ & 3 & 6.407 & 6.371 & $1.44 \sim 22.03$ & $1.43 \sim 21.91$ \\
\hline 3000 & $\begin{array}{l}2.30 \sim 13.23 \\
\%\end{array}$ & 6 & 0.712 & 0.711 & $1.41 \sim 8.14$ & $1.41 \sim 8.13$ \\
\hline 5000 & $\begin{array}{l}6.83 \sim 28.37 \\
\%\end{array}$ & 10 & 0.256 & 0.256 & $1.51 \sim 6.27$ & $1.51 \sim 6.27$ \\
\hline
\end{tabular}

Table 9 is based on communication of SQPSK Rate 1/2 LDPC, 3Mcps, $2 \mathrm{~W}$ flight PA, daughter zero dBi antenna gain, mother $\mathrm{G} / \mathrm{T}$ : $-27 \mathrm{~dB} / \mathrm{K}$, link margin $2 \mathrm{~dB}$, with daughters keeping $100 \%$ communication with the mothership when they are within the max-supported slant range. 
Table 10. Data Volume Versus Slant Range for 7/8 LDPC.

\begin{tabular}{|c|c|c|c|c|c|c|}
\hline \multirow{3}{*}{$\begin{array}{c}\text { Max- } \\
\text { Supported } \\
\text { Mother-to- } \\
\text { Daughter } \\
\text { Slant } \\
\text { Range } \\
\text { (km) }\end{array}$} & \multirow{3}{*}{$\begin{array}{c}\text { Probability } \\
\text { That } \\
\text { Daughter } \\
\text { Cubesat Is } \\
\text { Within This } \\
\text { Slant } \\
\text { Range }\end{array}$} & \multirow{3}{*}{$\begin{array}{l}\text { Maximum } \\
\text { Number of } \\
\text { Daughters } \\
\text { Within This } \\
\text { Slant Range }\end{array}$} & \multicolumn{2}{|c|}{$\begin{array}{l}\text { Maximum Achievable Data Rate } \\
\text { (per Daughter, Kbps) }\end{array}$} & \multicolumn{2}{|c|}{$\begin{array}{l}\text { Maximum Achievable Daily Data Volume } \\
\text { (per Daughter, Mb) }\end{array}$} \\
\hline & & & \multirow[t]{2}{*}{1 Daughter } & Max \# of Daughters & \multirow[t]{2}{*}{1 Daughter } & Max \# of Daughters \\
\hline & & & & $\begin{array}{c}\text { All effectively at Max- } \\
\text { Supported Slant } \\
\text { Range via Power } \\
\text { Control }\end{array}$ & & $\begin{array}{c}\text { All effectively at Max- } \\
\text { Supported Slant } \\
\text { Range via Power } \\
\text { Control }\end{array}$ \\
\hline 250 & $0 \sim 0.13 \%$ & 1 & 61.771 & 61.771 & $0 \sim 6.94$ & $0 \sim 6.94$ \\
\hline 1000 & $0.26 \sim 3.98 \%$ & 3 & 3.861 & 3.839 & $0.87 \sim 13.28$ & $0.86 \sim 13.20$ \\
\hline 3000 & $\begin{array}{l}2.30 \sim 13.23 \\
\%\end{array}$ & 6 & 0.429 & 0.428 & $0.85 \sim 4.90$ & $0.85 \sim 4.89$ \\
\hline 5000 & $\begin{array}{l}6.83 \sim 28.37 \\
\%\end{array}$ & 10 & 0.154 & 0.154 & $0.91 \sim 3.77$ & $0.91 \sim 3.77$ \\
\hline
\end{tabular}

Table 10 is based on communication of SQPSK Rate 7/8 LDPC. The other parameters are the same as in Table 9. As shown in Tables 9 and 10,1/2 LDPC is better than 7/8 LDPC for data rate, and total daily data volume. It ts due to the coding gain of $1 / 2 \mathrm{LDPC}$ being better than $7 / 8$ LDPC. If there is only one daughter, the maximum achievable data rate in columes four and five are the same. If there are more than one daughter, the maximum achievable data rate is reduced slightly due to mutual interference. The same is true for the maximum achievable daily data volume.

With the CDMA signal design, as shown in Tables 9 and 10, the constellation mother/daughter architecture is able to produce an adequate daily data volume if the daughter and mother ship CubeSats are in a coordinated orbit (for instance, formation flying).

If the mother/daughter CubeSats are in un-synchronization orbit, in order to downlink a meaningful/adequate daily volume of science data, the use of a mother CubeSat as a store-forward relay requires intelligent protocols capable of performing efficient management and operation control of signal flow for the inter-satellite links. Cognitive radio/adhoc networking is a potential candidate technique for providing the functions necessary for an autonomous CubeSat inter-satellite communication network management system.

Cognitative radios with intelligent protocols offer a potential solution for managing NEN direct to ground communication support of CubeSats constellations in non synchronized orbits without a Mother/Daughter architecture. This could lessen the load on scheduling system personnel.

While large aperture ground antennas (i.e. $>10 \mathrm{~m}$ ) maximize the data rate and minimize the flight hardware power required for CubeSats, NEN small aperture wide beam ground antennas (i.e. $<7.3 \mathrm{~m}$ ) have the potential for use to find CubeSats launched in a swarm of other CubeSats during launch and early orbit, whether these CubeSats are in constellations or not. The addition of small aperture ground stations also have other advantages for both CubeSats and traditional non-CubeSat missions for NEN. They are significantly lower in cost than larger aperture stations and would free up larger aperture stations for the missions that need them. The mission requiring larger apertures are CubeSats with limitations in flight transmitter power, and non-CubeSat traditional missions at longer distances (e.g. Lunar and L1/L2).

\section{Space Network CubeSat Support}

This sections discusses support of CubeSats by the Space Network (SN) via the Tracking and Data Relay Satellite System (TDRSS). TDRSS support will be limited by lower data rate due to power constraint on the spacecraft and the distance between the spacecraft and the satellite relay. TDRSS can provide global coverage to CubeSats with low latency, compared to limited contact time with just ground stations. More coverage time via TDRSS mitigates the power constraint by using lower data rates to deliver more data than brief, intermittent ground station contacts. It is ideal for emergency support. A CubeSat could send status alerts instantly without waiting until a ground station is in view.

The TDRSS legacy S-band Multiple Access (SMA) service is able to support a CubeSat data rate at $1 \mathrm{kbps}$ with practical spacecraft power amplifier of $2 \mathrm{~W}$ and a patch antenna with zero dBi gain. With newer TDRSS HIJ SMA (second generation, higher TDRS EIRP), the support data rate is little higher to $1.3 \mathrm{kbps}$ rate (same CubeSat EIRP).

American Institute of Aeronautics and Astronautics 
TDRSS Mutliple Access (MA) arraying with at least two TDRS in view is able to support an even higher data rate (15 kbps with a $3 \mathrm{~W}$ PA and $0 \mathrm{dBi}$ antenna gain). The arraying capability has been demonstrated multiple times. It was demonstrated with both Swift and Fermi missions. The SN would support arraying for CubeSat missions for any mission deemed important enough to NASA. A CubeSat constellation demonstration mission using MA, consuming TDRS Unused Time, and scheduled throught the Demand Access System at White Sands would be endorsed by the $\mathrm{SN}$.

In order for CubeSats to use TDRSS S-band Single Access (SSA) and Ka-Band Single Access (KaSA) support, they need a deployable high gain antenna on board to produce positive link margin. An EIRP of $13 \mathrm{~dB}$ is required to produce a $1 \mathrm{~dB}$ link margin for SSA return $100 \mathrm{kbps}$ data rate. For KaSA support, a data rate of $39.5 \mathrm{Mbps}$ is achieved with a $2 \mathrm{~W}$ PA and a $36 \mathrm{dBi}$ deployable antenna with OQPSK and rate 1/2 LDPC coding. The data rates will be reduced to $19.45 \mathrm{Mbps}$ if rate $1 / 2$ convolutional code is used.

Figure 11 iillustrates how the SN and NEN together could support various CubeSat communication architectures. Although there is far greater space loss when using TDRSS than when using the NEN or other ground-based communication options, a key advantage of using TDRSS is that multiple relay satellites are in-view for virtually any CubeSat orbital location.

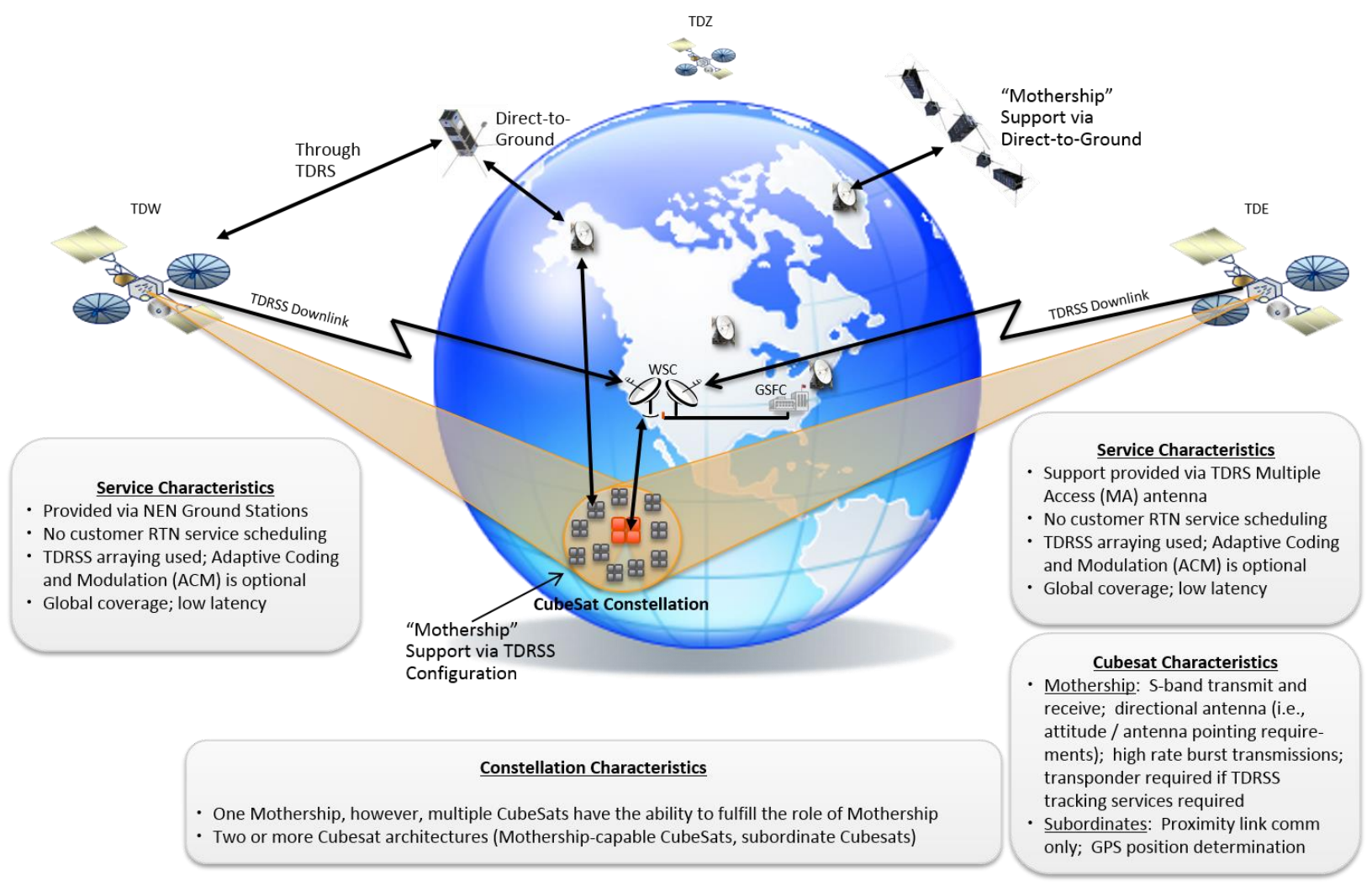

Figure 11. SN and NEN Supports Supports both Single CubeSats and CubeSat Constellations

\section{Conclusion}

The NEN and the SN are anticipating the needs of the CubeSat community with planned network enhancements and assistance to the CubeSat community of transitioning to flight hardware which best capitalizes on existing assets. The NEN has capacity to add additional CubeSat missions, will take advamtage of developments by commercial partners, and will explore adding assets which best meet evolving mission needs. Boith the NEN and the SN are investigating streamlining mission planning, integration, and test, to save costs and reduce the lead time, for all missions, whether CubeSat or not.

Today, the Wallops 18-meter UHF CubeSat groundstation has enabled three Mbps (the highest data rate proven with publicly available flight hardware) for CubeSats with $1-2 \mathrm{~W}$ of transmit power ${ }^{8}$. Lack of publicly available Sband (1 Mbps) until recently, and X-band (10's of Mbps) CubeSat radios have prevented the widespread use of NEN

American Institute of Aeronautics and Astronautics 
and SN. Once public S-band (1-10 Mbps) and X-band (10's of Mbps) radios become proven for CubeSats, more missions may use the NEN and SN.

Some CubeSats, particularly of high science return and sophistication, may desire the high data rates of traditional non-CubeSat satellites, but are more constrained in flight power and volume for antennas than traditional non-CubeSat satellites. NEN currently has $11 \mathrm{~m}$ class apertures worldwide. Simulations with current CubeSat technology flight antennas and radios, show that even $11 \mathrm{~m}$ class apertures do not have the performance to maximize data rates over Xband in LEO orbits. Improvements in flight hardware as well as ground systems could support very high rate (10's of Mbps) CubeSat missions in LEO orbits. Deployable high gain antennas on-board CubeSats will enable high data rate missions through NEN and SN.

Simulations also show that some traditional NEN non-CubeSat LEO missions have significant margin to make use of smaller apertures. Smaller apertures for traditional (non-CubeSat) missions and low data rate CubeSat missions could free up larger apertures for those missions that need them.

NEN supports LEO, Lunar and L1/L2 CubeSats and non-CubeSat traditional missions. Lunar, L1/L2, and even LEO CubeSat missions may require larger than 11-meter class apertures. Large apertures (e.g. $18 \mathrm{~m}, 21 \mathrm{~m})$ may be added to NEN via commercial services. .

\section{Acknowledgments}

The authors wish to thank NEN, SN, and GSFC for funding CubeSat investigation initiatives. The authors also wish to thank Polly Lynn for editing assistance.

\section{References}

${ }^{1}$ Satellite Industry Association (SIA), "State of the Satellite Industry Report 2015".

${ }^{2}$ SpaceWorks, "2014 Nano/Microsatellite Market Assessment".

${ }^{3}$ Scott Schaire, Serhat Altunc, "CubeSat Communication Direction and Capabilities at Morehead State University and NASA Goddard Space Flight Center, Wallops Flight Facility”, Small Satellite Conference, NASA Goddard Space Flight Center, August, 2013.

${ }^{4}$ Tursunjan Yasin, "Transparent Antennas for Solar Cell Integration," PhD Dissertation, Utah State University, 2013.

${ }^{5}$ Mahmoud N. Mahmoud, "Integrated Solar Panel Antennas for Cube Satellites," PhD Dissertation, Utah State University, 2010.

${ }^{6}$ T. Yasin,_R. Baktur, "Inkjet printed patch antennas on transparent substrates", 2010 IEEE Antennas and Propagation Society International Symposium (APSURSI), July 2010.

${ }^{7}$ Taha Yekan, et al. "Examination of Two Types of Quasi Transparent Reflectarray Elements," 2016 IEEE International Symposium on Antennas and Propagation, Fajardo, Puerto Rico, USA, June 2016 (submitted for publication).

${ }^{8}$ C.S. Fish, C.M. Swenson, G. Crowley, A. Barjatya, T. Neilsen, J. Gunther, I. Azeem, M. Pilinski, R. Wilder, D. Allen, M. Anderson, B. Bingham, K. Bradford, S. Burr, R. Burt, B. Byers, J. Cook, K. Davis, C. Frazier, S. Grover, G. Hansen, S. Jensen, R. LeBaron, J. Martineau, J. Miller, J. Nelsen, W. Nelson, P. Patterson, E. Stromberg, J. Tran, S. Wassom, C. Weston, M. Whiteley, Q. Young, J. Petersen, S. Schaire, C.R. Davis, M. Bokaie, R. Fullmer, R. Baktur, J. Sojka, M. Cousins, "Design, Development, Implementation, and On-orbit Performance of the Dynamic Ionosphere CubeSat Experiment Mission", Space Science Reviews, February 2014.

American Institute of Aeronautics and Astronautics 